\title{
Um Estudo sobre as Principais Dificuldades na Empregabilidade de um Engenheiro de Software
}

\author{
Edson M. Neto ${ }^{1}$, Julio C. Furtado ${ }^{1}$ \\ ${ }^{1}$ Departamento de Ciências Exatas e Tecnológicas - Universidade Federal do Amapá \\ (UNIFAP) \\ Rod. Juscelino Kubitschek KM-02 - 68.903-419 - Macapá - AP - Brazil \\ medson29@gmail.com, furtado@unifap.br
}

\begin{abstract}
This research seeks to make a study about the main aspects that influence the employability of a software engineer. After this stage a survey is carried out with the professionals of the area to ascertain the relevance of the difficulties raised. Knowledge gaps were in certain subjects regarding time of service and degree of schooling and optimism regarding the employable degree of obsolescence of professionals with a high degree of schooling.
\end{abstract}

Resumo. Esta pesquisa busca fazer um estudo sobre os principais aspectos que influenciam na empregabilidade de um engenheiro de software. Realizou-se um survey com os profissionais da área para averiguar relevâncias das dificuldades levantadas. Foram encontradas lacunas de conhecimento em determinadas matérias com relação ao tempo de serviço e grau de formação e o otimismo em relação ao grau empregável dos profissionais com alto grau de formação.

\section{Introdução}

Segundo Rocha e França (2016), a avaliação equivocada acerca da própria empregabilidade pode levar o profissional à obsolescência e posteriormente a perda do grau empregável. Este trabalho apresenta achados como as 4 áreas de maior conhecimento pelos profissionais e como o grau de formação pode ser um forte fator de controle para se manter no mercado. Este trabalho se propõe em sinalizar lacunas de conhecimento entre o meio acadêmico e o mercado de trabalho com o objetivo de guiar possíveis trabalhos didáticos que amenizem as carências da formação acadêmica.

\section{Survey}

O público-alvo são profissionais na área de engenharia e software no país com finalidade de avaliar aspectos da empregabilidade da engenharia de software em organizações de software brasileiras. Alunos não graduados ficam de fora do público-alvo por não poderem atuar formalmente no mercado. A coleta de dados foi realizada por meio da lista geral de e-mails da Sociedade Brasileira de Software.

A referência é o currículo de engenharia de software da ACM/IEEE (2015), que define 11 áreas de conhecimento base: Processo de Software; Qualidade de Software; Gerenciamento de Projeto de Software; Ferramentas e Ambientes; Engenharia de Requisitos; Projeto de Software; Desenvolvimento de Software; Verificação e Validação; Evolução de Software; Confiabilidade de Software e Métodos Formais. 
Com relação às habilidades não-técnicas, no trabalho de França e Mellet (2016), foram definidas 3 habilidades: Fluência em Inglês; Boa Comunicação e Habilidades Interpessoais, escutar, trabalhar em grupo, persuasão, apresentar, emocional.

Em França e Rocha (2016) foram verificados aspectos na obsolescência dos profissionais e na percepção de empregabilidade. Em Lethbridge (2000) foram obtidas inspiração para as perguntas relacionadas ao conhecimento do público antes e depois da atuação no mercado.

\subsection{Instrumentação}

Os dados sobre os elementos são de caráter quantitativo. As questões objetivas expostas na Tabela 1, seguem a escala tipo Likert, com numeração de 1 a 5, sendo 1 relativo a muito baixa e 5 relativo a muito alta. Optou-se pela ferramenta Google Forms.

Tabela 1. Perguntas do Questionário

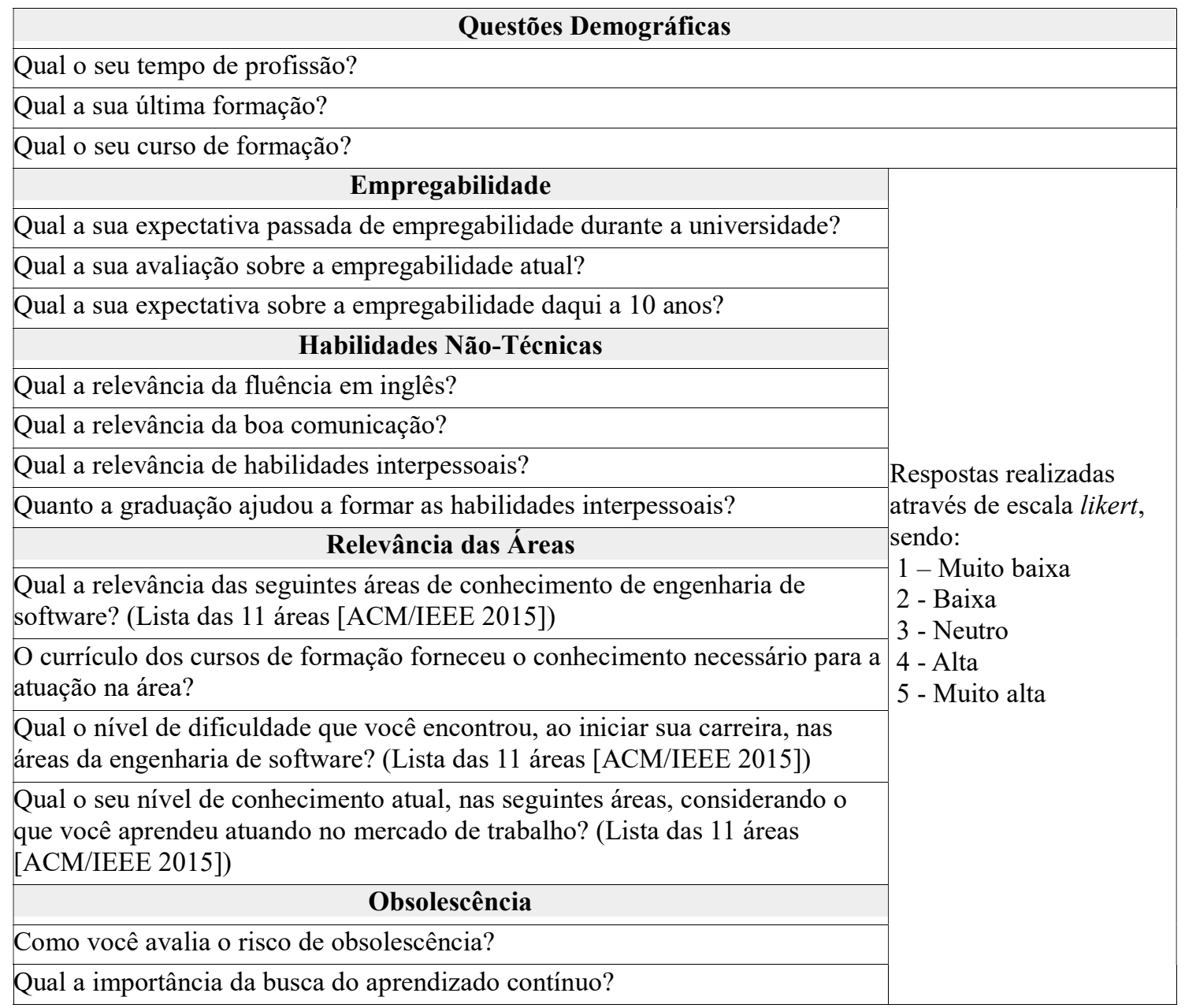

\section{Resultados e Discussão}

A pesquisa teve início no mês de agosto de 2017, sendo finalizada no mês de novembro de 2017. Nesse período foram coletados o total de 49 respostas. O curso de Ciência da Computação representa a maioria dos participantes, 59,18\%. O grau predominante de formação é o Mestrado (42,86\%), seguido de Doutorado (24,49\%) e Especialização $(20,41 \%)$. Destes profissionais, o tempo médio de profissão, é acima de 20 anos para 
$34,69 \%$, enquanto $26,53 \%$ atuam de 15 a 20 anos e $24,49 \%$ de 10 a 15 anos.

O grau de empregabilidade, na área possui uma perspectiva otimista, com 38,78\% dos pesquisados acreditando que possuem um alto grau de empregabilidade durante a universidade, $38,78 \%$ muito alto daqui a 10 anos e uma média de $28,57 \%$ um alto grau atualmente.

A grande maioria, 77,55\%, acredita na alta importância da busca do aprendizado contínuo. O risco de obsolescência é médio para $30,61 \%$ dos profissionais e alto para $26,53 \%$. Em relação ao quanto o currículo dos cursos forneceu conhecimento para atuar na área, $51,02 \%$ consideraram esse quesito médio.

Em relação as habilidades não-técnicas, a maioria dos entrevistados considerou muito importante a fluência em inglês, $71,43 \%$; a boa comunicação $63,27 \%$; e as habilidades interpessoais $57,14 \%$. No entanto, $32,65 \%$, consideraram que a graduação ajudou medianamente na formação dessas habilidades.

Nas áreas de conhecimento é possível ver que algumas áreas se pronunciam mais que outros no nível 5, como Engenharia de Requisitos e Desenvolvimento de Software, ambos com 59,2\%. Métodos Formais por outro lado não mantém um nível alto de relevância, onde a maior parte dos participantes classificou $2(20,4 \%), 3(28,6 \%)$ e 4 $(24,5 \%)$.

Sobre qual o nível de dificuldade encontrado ao iniciar sua carreira, nas áreas da engenharia de software, a maior parte das áreas recebeu nível de dificuldade moderado, próximo ao nível 3. Essa tendência se mantém para todas as áreas pesquisadas.

Sobre o quanto o currículo dos cursos de formação na Engenharia de Software forneceu conhecimento para atuação na área. Metade dos participantes classificou a pergunta no nível 3 (51\%), onde a formação acadêmica do engenheiro forneceu um nível de conhecimento moderado.

É aplicado o coeficiente de correlação de postos de Spearman, que é um método não-paramétrico usado para comparar a relação entre variáveis contínuas ou ordinais, Corder e Foreman (2009). A relação entre as variáveis é medida pela variação de -1 e 1 , sendo perfeita em 1; forte em 0.5 ; moderada em 0.3 ; fraca em 0.1 ; e nenhuma em 0 .

\subsection{Nível de Conhecimento Atual}

Quando é analisado a dependência do nível de conhecimento atual das 11 áreas de conhecimento, variáveis ordinais com base na escala Likert, com relação a variável ordinal independente Tempo de Profissão, é encontrado relações fortes positivas em Processo de Software $(\rho=0,64)$, Qualidade de Software $(\rho=0,57)$, Gerenciamento de Processos de Software $(\rho=0,65)$ e Projeto de Software $(\rho=0,56)$, onde quanto maior o tempo de profissão, maior será o nível de conhecimento atual dado pelo profissional.

Em contrapartida, a correlação da variável independente ordinal Grau de Formação não apresenta relações fortes sobre as variáveis, dependentes ordinais com base na escala Likert, do nível de conhecimento atual das 11 áreas de conhecimento. Em Processo de Software $(\rho=0,32)$, Qualidade de Software $(\rho=0,20)$, Gerenciamento de Processos de Software $(\rho=0,24)$ houveram correlações fracas, mostrando que o Grau de Formação não influencia no grau de conhecimento atual dado pelos profissionais na escala Likert destas matérias. Havendo apenas uma correlação positiva moderada em Projeto de Software $(\rho=0,46)$, talvez devido ao caráter de que para um grau maior de 
formação, esta matéria esteja entre as principais para se ter domínio da área.

\subsection{Empregabilidade}

A variável independente e ordinal Grau de Formação possui correlação forte positiva sobre as variáveis, dependentes e ordinais com base na escala Likert, de expectativa de empregabilidade. A correlação é moderada positiva durante a universidade $(\rho=0,34)$ e num período de 10 anos $(\rho=0,42)$, porém a correlação é posivita forte na data atual $(\rho=$ $0,50)$, onde quanto maior o grau de formação, maior será o nível de expectativa de empregabilidade dado pelo profissional na escala Likert.

Diferentemente, a variável independente e ordinal Tempo de Profissão não possui correlação com as variáveis dependentes e ordinais de expectativa de empregabilidade. Sendo nulo $(\rho=0,07)$ durante a universidade, positivo moderado $(\rho=0,30)$ atualmente e muito fraco $(\rho=0,15)$ daqui a 10 anos. Onde o tempo de profissão não determina o nível de expectativa de empregabilidade que o profissional percebe.

Isso demonstra como o grau de formação se apresenta como um forte fator de controle para se manter no mercado, como apresenta Rocha e França (2016). Sendo uma ótima sugestão as empresas da área e aos profissionais, dedicar um plano de carreira com base no constante desenvolvimento curricular.

\subsection{Habilidades não-técnicas}

Comparado com a variável independente e ordinal Grau de Formação do profissional, verificou-se um grau positivo moderado em relação a variável, dependente e ordinal com base na escala Likert, fluência em inglês $(\rho=0,35)$. Fatores como habilidades interpessoais, variável dependente e ordinal com base na escala Likert, $(\rho=0,0046)$, boa comunicação, variável dependente e ordinal com base na escala Likert, $(\rho=0,18)$ e em quanto o currículo ajudou na formação destas habilidades, variável dependente e ordinal com base na escala Likert, $(\rho=0,26)$, apresentaram correlação fraca ou nula, de modo que o grau de formação não influencia no nível de relevância das habilidades não-técnicas dado pelos profissionais.

Estes dados reforçam o trabalho de França e Mellet (2016), onde o meio acadêmico não trabalha as competências não-técnicas dos profissionais.

Não significa que não sejam habilidades importantes, visto a demanda obtida no trabalho de França e Mellet (2016) e os resultados vistos no survey, porém, tanto o tempo de profissão quanto o grau de formação não são fatores que modifiquem a relevância das habilidades não-técnicas.

\subsection{Dificuldades encontradas}

Sobre o risco de obsolescência, variável dependente e ordinal com base na escala Likert, $(\rho=0,33)$, a correlação com a variável independente e ordinal Tempo de Profissão, se apresenta de forma moderada, não sendo possível afirmar que o tempo de profissão determine a percepção do risco de obsolescência do profissional. Em relação a busca do aprendizado contínuo, variável dependente e ordinal com base na escala Likert, e a variável independente ordinal Tempo de Profissão essa correlação é fraca $(\rho=0,26)$. Como visto na seção $3,77,55 \%$ dos profissionais consideram este fator muito relevante, a correlação demonstra que a relevância da busca do aprendizado contínuo independe do tempo de carreira. 
Com base na variável independente e ordinal Grau de Formação e as variáveis dependentes e ordinais com base na escala Likert, risco de obsolescência $(\rho=-0,015)$ e busca de aprendizado contínuo $(\rho=0,17)$ apresentaram correlações muito fracas ou nulas. De modo que o grau de formação não interfere na percepção do risco de obsolescência do profissional e nem na relevância da busca do aprendizado contínuo.

Outra correlação está na variável dependente e ordinal é o quanto o currículo dos cursos forneceu conhecimento necessário na área de atuação em relação a variável independente e ordinal Grau de Formação, que resultou numa correlação fraca ( $\rho=$ 0,187), de modo que o grau de formação não afeta no nível que o profissional avalia o quanto o currículo dos cursos forneceu conhecimento.

\section{Considerações finais}

Não foram constatados nessa pesquisa que as diferenças de grau de conhecimento entre as variáveis de Grau de Formação e Tempo de Profissão afetem a auto percepção do grau empregável do profissional, visto que essa lacuna de conhecimento abrange aprendizados externos ao ambiente acadêmico. Porém, é proposto uma melhor instrução dos profissionais da área para desenvolvimento curricular com objetivo a aumentar sua perspectiva de empregabilidade e um maior foco dos cursos de formação para o aprendizado de habilidades não-técnicas devido a importância deste tanto por profissionais quanto empregadores.

\section{Referências}

ACM/IEEE. (2015) "Software Engineering 2014: Curriculum Guidelines for Undergraduate Degree Programs in Software Engineering", https://www.acm.org./binaries/content/assets/education/se2014.pdf, February.

Corder, G. W., Foreman, D. I. (2009), Nonparametric Statistics For Non-Statisticians: A Setp-by-Step Approach. John Wiley \& Sons, Inc., 1 th edition.

França, C., Mellet, D. (2016) "Soft Skills Required! Uma Análise da Demanda por Competências Não-Técnicas de Profissionais para a Indútria de Software e Serviços", IX Fórum de Educação em Engenharia de Software do XXX Simpósio Brasileiro de Engenharia de Software, pages 101-112, Maringá, PR, Brazil, Setembro.

Lethbridge, T. C. (2000) "What Knowledge is Important to a Software Professional", Journal IEEE Computer Society Press Los Alamitos, CA, USA, pages 44-50, Volume 33 Issue 5, May.

Pressman, R. S. (2011), Engenharia de Software: Uma Abordagem Tradicional. AMGH, 7 th edition.

Rocha, B. S. and França, C. (2016) “Auto Percepção da Empregabilidade em Engenheiros de Software”, IX Fórum de Educação em Engenharia de Software do XXX Simpósio Brasileiro de Engenharia de Software, pages 1-12, Maringá, PR, Brazil, Setembro.

Rocha, B. S. and França, C. (2016) "Obsolescência profissional em engenheiros de software: Uma revisão sistemática da literatura", IX Fórum de Educação em Engenharia de Software do XXX Simpósio Brasileiro de Engenharia de Software, pages 77-88, Maringá, PR, Brazil, Setembro.

Sommerville, I. (2011), Engenharia de Software. Pearson Brasil, 9th edition. 